\title{
The other side of sorrow: physician reflections on assisted dying
}

\author{
Cite as: CMAJ 2018 February 12;190:E169-70. doi: 10.1503/cmaj.171114
}

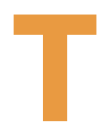

he Leonard Cohen lyric "I greet you from the other side of sorrow and despair" captures the common goal of all physicians to relieve suffering in our patients. Not surprisingly, medical assistance in dying (MAiD), which became legal in 2016, is a topic of intense debate. A 2015 survey by the College of Family Physicians of Canada found that most physicians felt unprepared to provide it, and one-third stated they would refuse to participate. ${ }^{1}$ We were ambivalent about providing MAiD. This is a description of that experience from the perspectives of a palliative care physician and a cancer psychiatrist.

\section{Michael}

The first time I met Michael, he made a great effort to sit up in bed, saying he wanted "to be at eye level in order to maintain my dignity for this most difficult of conversations." Michael was weak with anemia and fatigue, and he was tangled in tubes; a unit of blood trickled into his veins. Despite these overt signs of weakness, he had a dignified and commanding presence. Michael had been a highly successful entrepreneur, who described himself as "fiercely independent" his whole life.

Michael chose his words carefully; breathlessness from his cancer made it challenging for him to speak in long sentences. He was not anxious about death. He was direct, forthright and keen to describe to me what he wanted the end of his life to look like. "I need you to understand that I get the final say in how this ends. I need you to hear that my suffering must not go on. I refuse to allow the death of my consciousness to occur before the death of my body." I was humbled by Michael's strength and clarity on the subject of dying, a subject I was only beginning

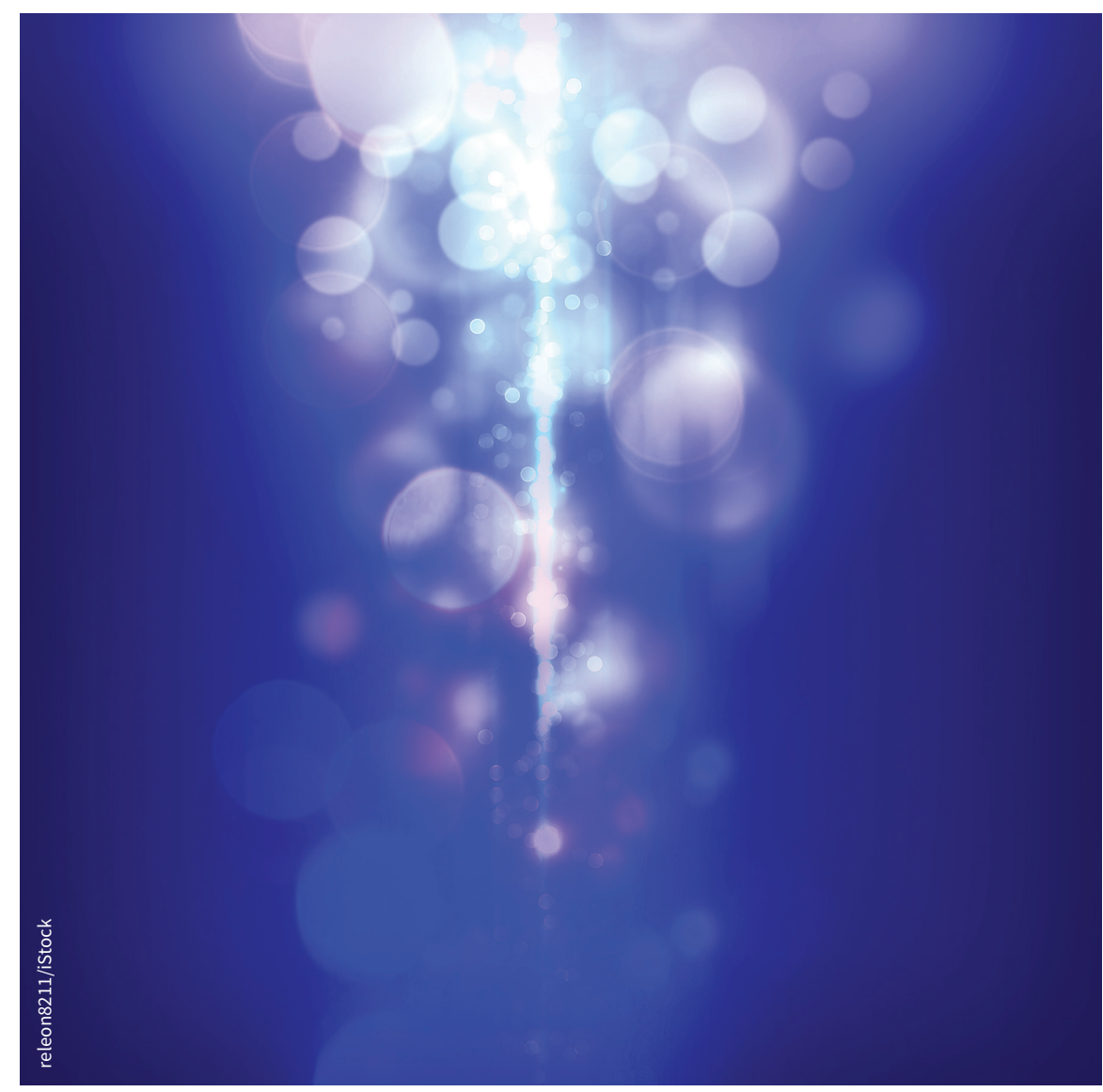

to grow comfortable with, in spite of my years of training.

We spent the next hour exploring his reasons for pursuing MAiD, talking about his life, what he valued and what he would miss. Michael told me he didn't want to die, but what he did have some control over was the manner and timing of his death. Michael explained that he did not want palliative sedation, whereby a physician administers sedating medications for a patient with intractable symptoms who is not expected to live long. He considered the "death of my consciousness" an affront to his dignity and personhood. He was "repulsed by being physically present but cognitively absent," essentially a "body in a bed." I had never heard a patient speak of palliative sedation in this way; in my experience, many patients felt relieved that they would no longer have to be awake and suffering.

Talking with Michael was profoundly personal and emotionally laborious work. Only an hour before, we had been strangers. Now, Michael had shared some of his most deeply held beliefs and perspectives on his life and his dying process. I checked the boxes marking him "eligible" to receive assistance in dying. My pen felt heavy in the silence that ensued during the time it took me to complete the paperwork, this 
task feeling strangely sterile and officious given the intimate nature of the conversation so recently finished.

Michael's great relief at being found eligible for MAiD was similar to the relief that patients in palliative care feel when they regain control through the use of patientcontrolled analgesia pumps for pain. But his request was not driven by inadequate control of physical symptoms. For him, access to MAiD was about autonomy and self-determination in the face of lifeshortening illness. After Michael learned he was eligible, he seemed to better tolerate his breathlessness. In the days before his death, he told me he had more patience and respect for the limitations of his body; knowing he had access to MAiD gave him back the agency over his living and dying that his cancer had taken from him.

On the day of Michael's MAiD intervention, the atmosphere in the room was far less sombre and upsetting than I had anticipated, in no small part because Michael was calm and unwavering in his decision. The procedure was brief. It felt surreal to me that only five minutes ago, this man had been fully alert and alive. Now, at his request and at the hands of the intervention physician, he intentionally lay lifeless. At the ensuing team debrief, I was struck by how rare it is for health care providers to be so deeply moved together; we realized that a medically assisted death could be both poignant and peaceful. I believed that I had helped Michael with his suffering, in the only way acceptable to him.

\section{Ellen}

Ellen had been admitted to hospital because of another bowel obstruction. There were no more surgical options, and it was estimated that she had fewer than three months to live. Her pain and nausea could be controlled with medications, but she said they clouded her thinking unacceptably. Ellen didn't want total parenteral nutrition: she felt it was futile, and she didn't want to waste away with the cachexia her malignant disease would inevitably bring. She described herself as a "stable, practical and pragmatic" person. She valued physical achievement, had run marathons, and now found it unbearable to be unable to walk; it was a constant reminder of how much of her identity and abilities she had lost. "I've had a fabulous life - this is just not me," she said. She was not depressed, and would not have considered suicide if MAiD were not available.

At the same time, Ellen was fearful of dying: she did not want counselling about death anxiety, she avoided end-of-life discussions and planning, and she didn't allow her friends or grandchildren to visit because of her distress levels. She did not want to know her prognosis, saying, "it would cause me more anxiety."

I struggled with Ellen's request for MAiD: I had helped relieve existential distress for many palliative patients, but I also knew I had to accept Ellen's right to refuse counselling. Ellen reacted with visible relief and gratitude when she learned she was approved for MAiD, saying, "I just feel so well now." With the certainty that MAiD was an option for her, Ellen was able to enjoy time with her family. She agreed to have her grandchildren visit and prepared farewell notes for them. It was an epiphany for me to realize that MAiD approval could be such a rapidly acting intervention for existential distress. MAiD may, in fact, have been the only effective intervention for her anxiety about death. Palliative psychotherapies are usually focused on legacy, meaning and dignity. Even if Ellen had been willing to engage in counselling, I wondered if her "practical and pragmatic" attitude meant that the approaches would only have reinforced her losses from cancer and strengthened her desire for MAiD.

Ellen was frustrated, however, by the legal requirement that she must be cognitively intact to give consent before administration of MAiD. This made choosing a date difficult, as she might have to give up days of competent life. During an episode of pain, she urgently asked for MAiD, and it was arranged for the following day. However, she changed her mind at the last minute, which surprised and distressed her family, staff and herself. The following day, without any evidence of delirium or opioid-induced confusion, Ellen said she did not remember having asked for MAiD and changing her mind, but she did say she no longer wanted it.

She became more receptive to a detailed discussion of the alternative of palliative sedation. She had been unaware that palliative sedation could be implemented more simply, on an urgent basis, and even given intermittently. She was also relieved to hear that she could make it an advance directive, and that it was given only in the last days to weeks of life, so she wouldn't be "languishing as a vegetable for months." In the end, Ellen died naturally, with family at the bedside describing her death as "quiet ... and peaceful."

Have MAiD cases become easier for us over time? Not really. Each case is still hard, and we agree that the moment MAiD starts becoming easy, that's the moment we will stop participating in it. Our initial fears that we would feel professionally invalidated by medical assistance in dying were resolved when we recognized it was not our wishes that mattered, but the patient's. Like our patients who have serious and life-limiting illness, our task is to adapt and learn from change. Reflecting on adversity and change, Leonard Cohen also wrote, "There is a crack in everything. That's how the light gets in."

\section{Madeline Li MD PhD}

Department of Supportive Care, Princess Margaret Cancer Centre, Toronto, Ont.

\section{Danielle Kain MA MD}

Department of Supportive Care, Toronto Western Hospital, University Health Network, Toronto, Ont.

\section{Reference}

1. CFPC ePanel 22015 Physician assisted suicide and euthanasia. Mississauga (ON): The College of Family Physicians of Canada; 2015. Available: www.cfpc. ca/ePanel/ (accessed 2017 Nov. 13).

This article has been peer reviewed.

The next of kin have provided consent for these stories to be told. To protect the identity of the patients, pertinent details have been changed. 